\title{
Crescimento do e-commerce no Brasil: desenvolvimento, serviços logísticos e o impulso da pándemia de Covid-19
}

\begin{abstract}
Resumo
O progresso técnico e sua difusão pelo território materializa-se na criação de novas redes, sejam elas de transportes, comunicação, distribuição etc. Produto da divisão social, territorial e internacional do trabalho, as redes estruturam e reestruturam as interações entre os indivíduos e o espaço constantemente. Nesse contexto, emerge o e-commerce como uma nova ferramenta de comercialização, marketing e distribuição de mercadorias. O objetivo deste artigo é demonstrar o processo de desenvolvimento do e-commerce no Brasil, bem como a relação dele com os serviços logísticos. Para que o e-commerce pudesse, de fato, difundir-se pelo território brasileiro foi necessário que, além das claras seguranças econômica e jurídica, houvesse um razoável aparato de redes e objetos técnicos. No entanto, não só o avanço das redes de comunicação e da melhoria do aparato técnico da população explicam a expansão do comércio eletrônico no Brasil, mas também questões conjunturais advindas das necessidades objetivas, como o caso do impulso dado ao e-commerce pela pandemia do Covid-19. Neste artigo sustentamos o argumento que o estudo da expansão do e-commerce no Brasil pode ser analisado a partir de três eventos: a expansão e a popularização das redes de internet, a difusão do uso de smartphones e os impactos da pandemia do Covid-19.
\end{abstract}

Palavras-chave: E-commerce, Logística, Covid-19, Brasil. 


\begin{abstract}
GROWTH OF E-COMMERCE IN BRAZIL: DEVELOPMENT, LOGISTIC SERVICES AND THE IMPULSE OF THE PANDEMIC OF COVID-19

Technical progress and its diffusion across the territory materializes in the creation of new networks, be they of transport, communication, distribution, etc. A product of the social, territorial and international division of labor, networks constantly structure and restructure interactions between individuals and space. In this context, e-commerce emerges as a new tool for the commercialization, marketing and distribution of goods. The purpose of this article is to demonstrate the development process of e-commerce in Brazil, as well as its relationship with logistics services. So that e-commerce could, in fact, spread throughout Brazilian territory, it was necessary that, in addition to clear economic and legal security, there should be a reasonable apparatus of networks and technical objects. However, not only the advancement of communication networks and the improvement of the population's technical apparatus explain the expansion of electronic commerce in Brazil, but also conjunctural issues arising from objective needs, such as the case of the impulse given to e-commerce by the pandemic of the Covid-19. In this article we support the argument that the study of the expansion of e-commerce in Brazil can be analyzed by three events: the expansion and popularization of internet networks, the spread of the use of smartphones and the impacts of the Covid-19 pandemic.
\end{abstract}

Key-words: E-commerce, Logistics, Covid-19, Brazil.

\title{
1. Introdução
}

No início da terceira década do século XXI, o Brasil e o mundo passam por mudanças radicais. Essas mudanças envolvem um leque de elementos, como o desenvolvimento tecnológico (automação dos processos logísticos e produtivos, informatização e digitalização do comércio, difusão do uso de aplicativos (Apps), customização de produtos etc.); crise política (acirramento do embate entre movimentos conservadores e liberais, como os casos da polarização política nos Estados Unidos, da Argentina e do Brasil); e a crise ambiental (cada vez mais aumenta a pressão internacional para o uso de fontes de energias limpas e renováveis entre os países). Além disso, não podemos esquecer que a pandemia do novo corona vírus (Covid-19) forçou a restruturação de diversas formas de interações sociais, espaciais e territoriais (MÉNDEZ, 2020). Neste contexto, o e-commerce deixou de ser 
uma tendência para tornar-se um hábito cotidiano de muitos brasileiros, sobretudo para os moradores das grandes e médias cidades (CRUZ, 2021).

Novaes $(2007)^{1}$ foi o autor que fez o primeiro grande estudo no Brasil que relacionava logística e comércio eletrônico, tornando-se uma leitura obrigatória para iniciantes no assunto. Na Geografia brasileira recente, alguns pesquisadores vêm realizando pesquisas sobre logística e transportes (de cargas e passageiros), dos quais entre os mais conhecidos podemos citar Ricardo Castillo², Márcio Rogério Silveira ${ }^{3}$, Roberto França Silva Junior ${ }^{4}$ e Nelson Fernandes Felipe Junior ${ }^{5}$, entre outros. Já no que se refere à análise do e-commerce e dos serviços logísticos relacionados, podemos destacar o trabalho de Cruz (2021) e as pesquisas que estão sendo desenvolvidas por Igor Venceslau ${ }^{6}$.

O objetivo deste artigo é demonstrar como se deu o desenvolvimento do e-commerce no Brasil, assim como a importância dele para o setor logístico, tendo por recorte temporal as duas primeiras décadas do século XXI. Nossa tese é que a análise do crescimento do e-commerce no Brasil pode ser justificada por três momentos basilares: $1^{\circ}$ ) O final da década de 2000 e início da década de 2010, quando houve a popularização do acesso à internet em lares e domicílios; $2^{\circ}$ ) A difusão do uso de smartphones no país, que acontece após o ano de 2015; $3^{\circ}$ ) A pandemia da Covid-19, iniciada no Brasil em março de 2020, que fez com que as pessoas optassem cada vez mais por receber seus produtos em seus domicílios, pois muitas passaram a evitar as inevitáveis aglomerações humanas dos centros comerciais tradicionais. Com o crescimento dos pedidos, o comércio eletrônico ganha cada vez mais protagonismo entre os prestadores de serviços logísticos (PSLs) que atuam no território brasileiro. Para a realização da pesquisa fizemos uma revisão bibliográfica referente à temática, buscamos relatos em mídias tradicionais e especializadas no assunto, além de buscarmos analisar dados sobre o e-commerce através da elaboração de gráficos e tabelas com base nos relatórios da Webshoppers ${ }^{7}$. 


\section{Entendendo o crescimento do e-commerce no Brasil}

O comércio eletrônico tem suas origens nos Estados Unidos na década de 1980, quando grandes varejistas e a indústria automobilística passam a utilizar o Electronic Data Interchange (EDI) para realizar os pedidos junto a seus principais fornecedores, pressionando toda a cadeia de suprimentos a se adequar e se modernizar do ponto de vista tecnológico. Posteriormente, em 1993, surgiram os softwares, que fizeram o uso dos computadores se tornar bem mais acessível. O conceito de browse ${ }^{8}$, introduzido pela Netscape nessa época, possibilitou a passagem de uma página eletrônica para outra com um simples clique do mouse, tornando bastante fácil a navegação. Novaes (2007) lembra que, a partir de 1994, as possibilidades de negócios na Web foram plenamente percebidas pelos agentes econômicos, iniciando-se assim uma nova fase, de cunho nitidamente comercial. Em 1995, já surgem algumas das empresas que se tornariam líderes do setor, como a eBay e a Amazon (SANTOS et al., 2018).

Na primeira década do séc. XXI, os principais tipos de e-commerce, de acordo com Novaes (2007), eram:

a) Comércio eletrônico através do uso de EDI (Electronic Data Interchange): é a transferência eletrônica e automática de dados entre os computadores das empresas participantes, dados esses estruturados dentro de padrões previamente acertados entre as partes. Na maioria dos casos, as redes de EDI são privadas, atendendo de forma exclusiva as firmas participantes. O EDI se tornou especialmente popular nas transações entre grandes empresas, que o utilizam para agilizar suas operações e implementar processos administrativos e operacionais na cadeia de suprimento. O EDI foi primeiramente adotado nos Estados Unidos, na década de 1980, pelos setores de varejo e de transporte. Mais tarde, se expandiu para os setores automotivo, farmacêutico e supermercadista. As três maiores montadoras automobilísticas norte-americanas exigiram que seus fornecedores, de primeiro, segundo e terceiro níveis hierárquicos (fornecedor (F1), fornecedor do F1 (F2) e fornecedor do F2 (F3)) adotassem o EDI. O mesmo se deu com a empresa varejista Wal-Mart; 
b) Comércio Eletrônico B2B: nesse tipo de transação eletrônica, as empresas fornecedoras desenvolvem páginas eletrônicas na Internet, através dos quais as empresas clientes podem obter e trocar informações com os fornecedores, como também adquirir os produtos. Assim, o comércio do tipo B2B se caracteriza por ter pessoas jurídicas nas duas pontas do processo, ou seja, a comercialização não é dirigida às pessoas físicas. Normalmente o B2B é utilizado para transações entre grandes empresas;

c) Comércio Eletrônico B2C: nesse tipo de transação, o comprador é uma pessoa física que, a partir de um computador pessoal, realiza suas buscas e adquire um produto ou serviço através da Internet. Por exemplo, um consumidor acessa o site de uma livraria, analisa os livros em oferta e acaba comprando um ou mais exemplares.

Bagatini e Laimer (2019) entenderam que, além das formas mais usuais de $\mathrm{EDI}, \mathrm{B} 2 \mathrm{~B}$ e B2C, existem formas de e-commerce, como o C2C (de consumidor para consumidor, como o caso do App OLX) e C2B (do consumidor para empresa ou logística reversa), entre outras formas embrionárias de negócios.

No início de sua implantação, o e-commerce ainda deixava muitos consumidores receosos, uma vez que o comércio digital é alicerçado em relações de confiança muito maiores que o comércio in loco, e muitas fraudes eram amplamente noticiadas. Hodiernamente, o consumidor, além de ter um leque de opções muito maior de páginas eletrônicas de vendas, também pode conferir as avaliações dos mesmos dada por outros usuários, seus feedbacks, rastrear seu produto etc., além das facilidades oferecidas pelos Apps de bancos para estornar transações fraudulentas. A ampliação da segurança dos usuários certamente tem grande parcela de contribuição para a expansão do número de adeptos do e-commerce.

$\mathrm{O}$ e-commerce também possibilita otimizar as estratégias de marketing dos fornecedores, uma vez que os mesmos podem ter acesso a dados que demonstram quais produtos estão sendo mais procurados, em quais períodos do ano determinadas mercadorias têm maior demanda, preferências de faixa etária ou sexo por determinados objetos etc., possibilitando aos lojistas se anteciparem às tendências de mercado 9 . 
Do ponto de vista geográfico, o e-commerce também é uma ferramenta que possibilita liberdade para o consumidor, pois o mesmo pode, através de seu smartphone ou computador, pesquisar preços e variedades dos produtos desejados em escala regional, nacional e global. Um exemplo claro é que hoje o consumidor pode comprar um acessório de moda nas páginas eletrônicas ou nos Apps da americana Wish e da singapurense Shopee, que enviam produtos da China para o mundo todo, em um intervalo de tempo menor do que o mesmo consumidor gastaria se fosse procurar o mesmo item nas tradicionais áreas de comércio dos centros urbanos, além, claro, da economia dos custos que o mesmo teria com deslocamento e estacionamento veicular. Em síntese, a escala geográfica da pesquisa que o consumidor realiza sobre o produto desejado é muito maior e em intervalo de tempo muito menor no e-commerce.

Outra vantagem do e-commerce é a personalização de produtos, nem sempre disposta no varejo convencional, por exemplo: se um indivíduo deseja adquirir uma camiseta de futebol e nela estampar o seu nome e colocar o número desejado, dificilmente ele conseguirá uma loja que faça esse serviço no momento da compra, diferentemente das opções em páginas eletrônicas especializadas em materiais esportivos, como a Netshoes e a Centauro, que oferecem a opção de customização dos produtos.

O primeiro passo para a difusão do comércio eletrônico foi a universalização do uso de Internet (acessibilidade à Internet) nos países. Evidentemente, nem todas as nações tiveram acesso à Internet difundido em seus territórios no mesmo intervalo de tempo, nem mesmo a qualidade e a velocidade da mesma é igual em todos os continentes. Países como os Estados Unidos, algumas nações mais desenvolvidas da Europa e a Austrália foram os primeiros a ter seus territórios contemplados com cabos de internet e redes móveis. Camargos (1997) afirma que, no ano de 1995, os países desenvolvidos concentravam cerca de $85 \%$ dos usuários de Internet no mundo. No ano de 2019, este cenário já se mostra bem diferente, pois os países em desenvolvimento representaram 73,1\% dos usuários de Internet no mundo, e $53 \%$ da população mundial já tem acesso à internet, de acordo com a União Internacional de Telecomunicações (ITU, 2019). 
Como podemos observar no gráfico 1, os países em desenvolvimento passaram os países desenvolvidos em número de usuários de Internet entre os anos de 2007 e 2008. China, Índia e Brasil ocupam, respectivamente, as posições de $1^{\circ}, 2^{\circ}$ e $4^{\circ}$ na lista dos países com maior número de usuários de Internet no mundo no ano de 2019 (ITU, 2019).

\section{Gráfico 1}

USUÁRIOS DE INTERNET EM PAÍSES DESENVOLVIDOS E EM DESENVOLVIMENTO (EM MILHÕES DE PESSOAS)

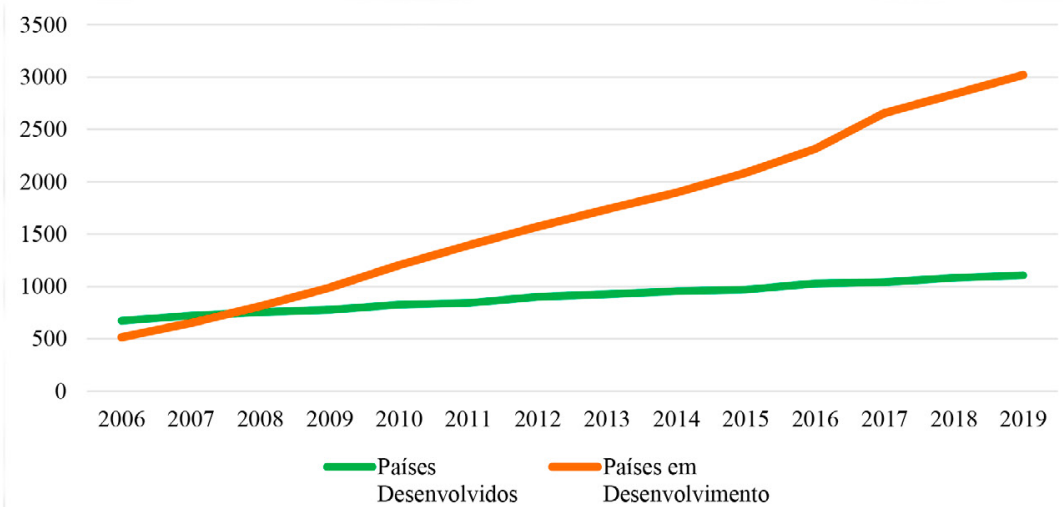

Fonte: Elaborado pelo autor com base em União Internacional de Telecomunicações (ITU), 2020.

Se, na metade da década de 1990, os Estados Unidos e alguns países desenvolvidos estavam criando seus primeiros canais de e-commerce, o Brasil ainda estava começando a experimentar o uso da internet. Segundo Santos et al. (2018), apenas em 1994 a Embratel decidiu implantar o acesso online de forma experimental no país, liberando-o para o setor privado somente em 1995. O Grupo Pão de Açúcar, Submarino e o Americanas. com foram os pioneiros no comércio eletrônico brasileiro (Idem).

A assimetria temporal da difusão das tecnologias que demandam Internet entre países desenvolvidos e em desenvolvimento levou alguns autores a diagnósticos não muito precisos sobre as razões do e-commerce não dar os resultados esperados na década de 2000 e até a metade da década seguinte no Brasil, como fizeram Novaes (2007) e Santos e Miranda (2015). Os últimos autores, inclusive, realizaram um estudo com o título "e-commerce no Brasil: se o segmento é promissor, por que empresas atuantes estão no vermelho?". Tanto Novaes (2007) quanto Santos e Miranda (2015) 
realizaram paralelos entre a situação do e-commerce de países desenvolvidos com a do Brasil, e diagnosticaram razões culturais, de gestão, adaptação das organizações ao modelo de negócio, razões financeiras, questão dos prazos de retorno, margens de lucro, padrões de contabilidade etc., como as principais causas do e-commerce no Brasil não ser rentável em sua primeira década de implementação. Em nosso entendimento, os autores não estão errados, mas dão demasiada ênfase às particularidades administrativas, organizacionais e culturais para uma questão cuja resposta se encontra, em grande medida, no campo histórico-geográfico, afinal as inovações tecnológicas têm um tempo de maturação diferente em formações econômico-sociais (FES) distintas.

De acordo com o Relatório da GV Executivo (2016), grande parte das empresas brasileiras tinham prejuízos com o e-commerce até o ano de 2014, quando a curva da relação entre faturamento e custos inverteu-se, e o negócio, de fato, passou a ser rentável. Esta realidade não foi singular no Brasil, pois, de acordo com o mesmo relatório, até mesmo a Amazon demorou sete anos para começar a obter lucros nos Estados Unidos depois de sua fundação em 1995. Muitas organizações que conseguiram a liderança no segmento cresceram com base na atração de investidores. Ou seja, captaram recursos de fundos de investimento. No entanto, na segunda década do século XXI, estas passaram a ser mais cobradas pela rentabilidade no Brasil (SANTOS; MIRANDA, 2015).

\section{Gráfico 2}

BRASIL: FATURAMENTO DO E-COMMERCE (2011-2020) EM R\$ BILHÕES

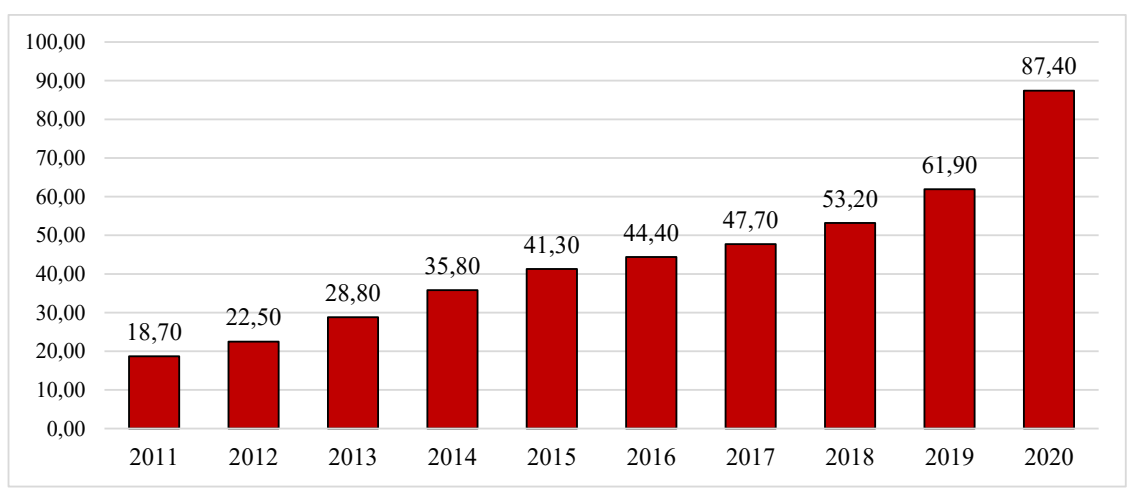

Fonte: Elaborado pelo autor com base em Webshoppers, 2021. 
Como podemos analisar no gráfico 2, o faturamento do e-commerce vem em ascendência no período 2011-2020, crescendo 351,3\%, com destaque para o ano de 2020, quando cresceu $41 \%$ em relação ao ano anterior. O relatório $n^{\circ} 43$ da Webshoppers (2021) salienta que a pandemia da Covid-19 contribuiu muito para a elevação dos números do e-commerce no Brasil, pois muitas pessoas passaram a buscar novas formas de adquirir mercadorias sem ter que frequentar os tradicionais pontos de compras. Mais adiante retomaremos esta discussão.

A Região Sudeste concentra mais da metade das vendas de e-commerce no Brasil (44,1\%), enquanto as demais Regiões representam 31,7\% (Nordeste), 13,1\% (Sul), 6,3\% (Centro-Oeste) e 4,7\% (Norte) no ano de 2020 (WEBSHOPPERS, 2021). Vale ressaltar que as Regiões Nordeste e Norte foram as que mais cresceram em faturamento de $e$-commerce em relação a 2019, aumentando suas participações no cenário nacional, respectivamente de $18,5 \%$ e $4 \%$ para 31,7\% e 4,7\% em 2020, enquanto as Regiões Sudeste, Sul e Centro-Oeste diminuíram sua participação no montante do país, que era de $52,6 \%, 18,3 \%$ e $6,6 \%$, respectivamente, passando para $44,1 \%, 13,1 \%$ e 6,3\% no mesmo período (idem).

Apesar do crescimento contínuo, Santos et al. (2018) destacam que o setor de e-commerce no Brasil só deixou de ser deficitário a partir de 2015. Os autores mostram que, além do aumento do número de usuários de Internet no país, outro fator foi determinante para o sucesso do e-commerce no Brasil: a difusão do uso de smartphones, que cresceu após a segunda metade da segunda década do séc. XXI, pois com os smartphones as estratégias de marketplace se tornaram mais eficientes, surgindo o e-commerce móvel, ou, na linguagem do meio logístico, "m-commerce". Se antes, para realizar uma compra digital, o consumidor tinha que estar em frente a um computador, com os smartphones basta que qualquer indivíduo esteja em qualquer lugar logado na Internet para que o mesmo possa realizar pesquisas de preços, serviços e compras.

O smartphone é um dispositivo que une funções de telefone, computador, máquina fotográfica, GPS etc. O mobile commerce (m-commerce) surgiu em 2010 como um novo tipo de mercado, oferecendo produtos e serviços de forma diferenciada, levando novos clientes a fazer compras eletrônicas, só que agora por meio de smartphones (SANTOS et al., 2018). 
No Brasil, foi no ano de 2013 que a venda de smartphones superou, pela primeira vez, a de celulares tradicionais. A introdução dos smartphones proporcionou mudanças não só nos hábitos de consumo:

\begin{abstract}
A união do e-commerce com o smartphone causou grandes transformações no padrão de compra dos consumidores e no modo como as empresas passaram a oferecer seus serviços. A conveniência desse aparelho mudou o modo como as pessoas se relacionam entre elas, e também modificou o comportamento entre as empresas e seus clientes, tornando a comunicação online mais comum (SANTOS et al., 2018, p. 1568).
\end{abstract}

A Webshoppers é a principal plataforma de dados e pesquisas sobre e-commerce no Brasil. Em pesquisa recente sobre marketplace, a Webshoppers divulgou quais os aplicativos digitais de redes sociais mais influenciam os usuários a realizarem compras digitais, apresentados na imagem 1 .

\title{
Imagem 1
}

PRINCIPAIS APLICATIVOS DIGITAIS QUE INFLUENCIAM NAS COMPRAS DE E-COMMERCE NO BRASIL EM 2019

\section{MOTIVADOR DE COMPRA 1S 2019 \\ REDES SOCIAIS}

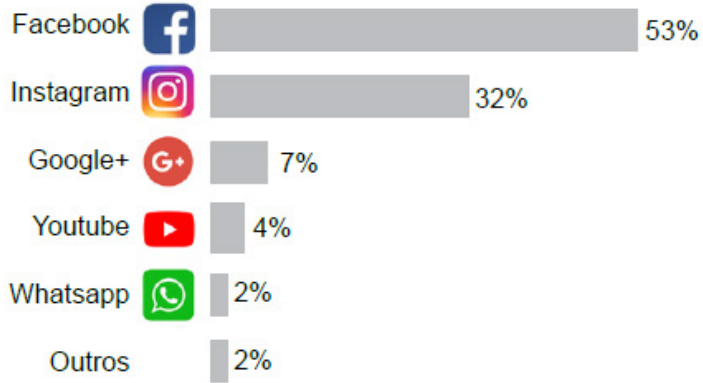

Fonte: Webshoppers, 2021.

Santos et al. (2018) defendem a tese de que a popularização dos smartphones, o crescimento do volume de acesso à Internet via aparelho de telefonia móvel e o aprimoramento das tecnologias associadas ao comércio eletrônico foram os principais responsáveis pela expansão do e-commerce brasileiro na segunda década do séc. XXI. Se analisarmos os números de novos usuários de e-commerce no país, podemos destacar um crescimento de 154,6\% no período entre os anos 2013 e 2020 (gráfico 3): 


\section{Gráfico 3}

BRASIL: NOVOS USUÁRIOS DO E-COMMERCE (2013-2020) (EM MILHÕES DE USUÁRIOS)

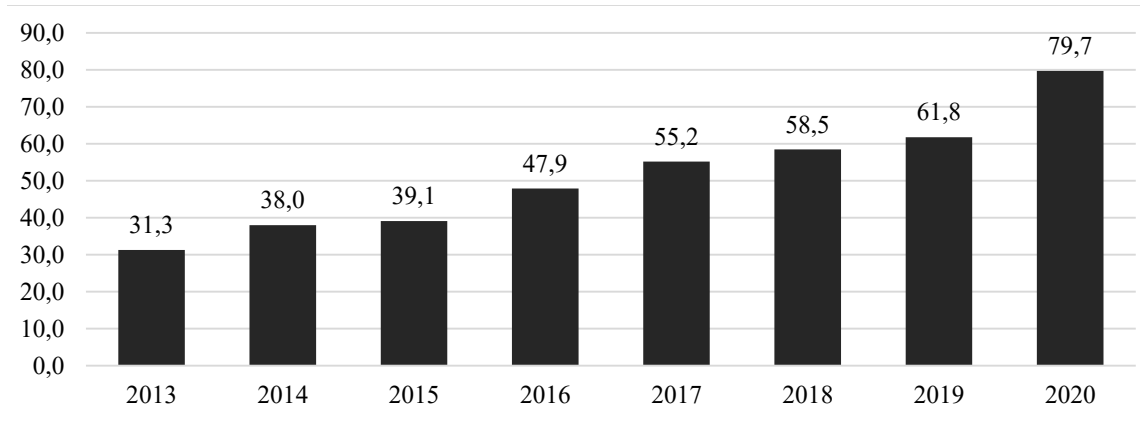

Fonte: Elaborado e organizado pelo autor com base em Webshoppers (2021).

Analisando-se o gráfico 3, podemos validar, com os devidos cuidados, a tese de Santos et al. (2018), pois o crescimento do número de usuários do e-commerce no Brasil aumenta consideravelmente justamente na segunda metade da década de 2010, período no qual, como bem lembram os autores, os smartphones passam a se popularizar no país.

Assim como o valor de faturamento e o número de usuários, os números de encomendas por e-commerce cresceram em uma grande velocidade na década de 2010, pois no ano de 2011 houve 54 milhões de encomendas no Brasil, enquanto dez anos mais tarde, em 2020, o número foi de 194 milhões, com crescimento de 259,2\% no período, com destaque para o ano de 2020, que teve o aumento de 30\% no número de encomendas em relação ao ano de 2019 (gráfico 4).

Washington Mora (Presidente da Ibex), em entrevista à Revista Tecnologística (2016), fez a seguinte análise sobre o crescimento do e-commerce no Brasil:

Todo mundo fala de crescimento do e-commerce, mas na verdade o que temos é uma migração de canal, uma mudança de comportamento do consumidor. No passado, as pessoas não se sentiam confortáveis em fazer uma compra pelo celular ou digitar o número do cartão de crédito em um site. Hoje, as novas gerações têm o cartão cadastrado em pelo menos 15 sites. As pessoas querem funcionalidade e comodidade (REVISTA TECNOLOGÍSTICA, 2016). 


\section{Gráfico 4}

BRASIL: NÚMERO DE ENCOMENDAS E-COMMERCE (2011-2020) (EM MILHÕES)

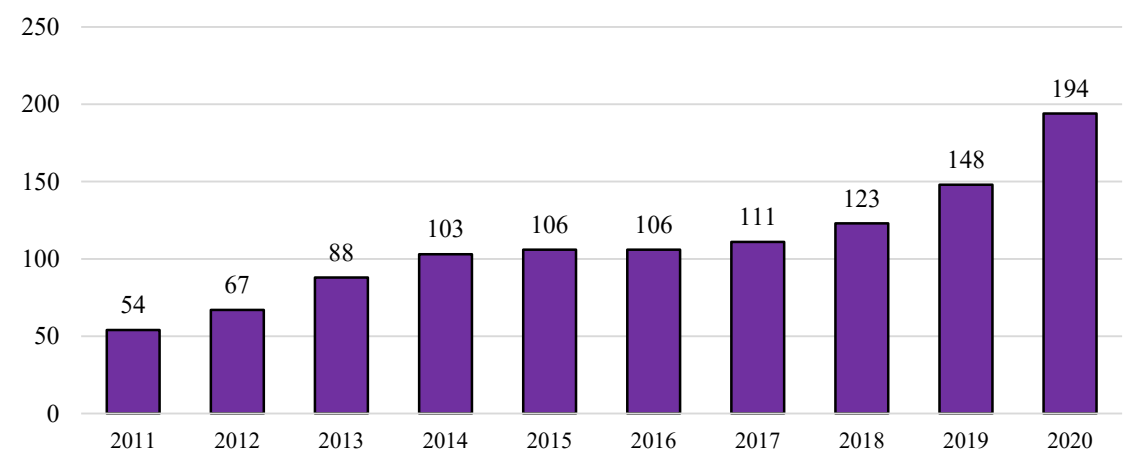

Fonte: Elaborado pelo autor com base em Webshoppers, 2021.

Atualmente, o Brasil conta com grandes empresas, nacional e mundialmente conhecidas, que representam grande parte da parcela das vendas online no Brasil, como a Amazon, a Polishop, o Walmart, o Magazine Luiza, as Casas Bahia, a Netshoes, a Dafiti e o Mercado Livre (WEBSHOPPERS, 2020). Bagatini e Laimer (2019) destacam que em 2014 haviam 360 mil lojas online no país, e já em 2018 os números haviam chegado a 675 mil, quase dobrando a quantidade de lojas. Os produtos mais vendidos pelo e-commerce brasileiro em 2018 são utensílios de moda e acessórios (18\%), perfumaria e cosméticos (18\%), alimentos e bebidas (3\%), acessórios automotivos (2\%), brinquedos e jogos (2\%) e petshop (2\%) (Idem).

\section{E-commerce, serviços logísticos e a pandemia da Covid-19}

Podemos nos perguntar por que analisar o e-commerce é tão importante para compreender os prestadores de serviços logísticos (PSLs) no Brasil? A resposta é que cada transação e-commerce necessita de agentes que fiquem encarregados de organizar a armazenagem, a distribuição e a entrega de cada produto vendido on-line, e esses serviços raramente são ofertados pelo vendedor, sendo normalmente atribuídos a alguns PSLs e operadores logís$\operatorname{ticos}^{10}$. O crescimento do e-commerce tem impactado fortemente o catálogo de serviços dos operadores logísticos, tanto nacionais quanto estrangeiros, 
como os casos da Peske, da Sequoia, da Total Express, da Ceva Logístics, do Fedex, da FM Logístic, do ID do Brasil e de outros ${ }^{11}$, que colocam o e-commerce como uma de suas principais atividades de atuação.

O serviço Correios Log é um importante serviço da Empresa Brasileira de Correios e Telégrafos (ECT), popularmente conhecida no Brasil apenas como "Correios". Criado em setembro de 2016, substituindo, em partes, o extinto e-Sedex. Em 2017, o serviço alterou o nome para Correios Log +. A função do Correios Log + é atender os pequenos e-commerces, permitindo que essas lojas virtuais mantenham seus estoques de produtos nos armazéns logísticos da ECT, e esta, por sua vez, se responsabiliza por atender os pedidos vendidos, fornecer embalagens para cada encomenda, preparar, expedir e distribuir diretamente para o comprador em todo o território nacional. Para a realização destas operações, a ECT se tornou intermodal, ou seja, realiza operações complexas utilizando todos os modais de transporte disponíveis de modo articulado. Silva Junior e Olegário (2016) recordam que no passado a aviação cumpriu um papel de integração territorial, mas atualmente ela cumpre um papel de integração logística. Os veículos leves e motocicletas são utilizados nos centros urbanos e áreas metropolitanas, enquanto que os veículos pesados são empregados para interligar a capital aos municípios do mesmo estado, podendo ainda transportar cargas consolidadas na mesma área de atuação dos equipamentos leves. As linhas aéreas dedicadas aos Correios operam somente em âmbito nacional. O transporte aéreo tem por finalidade executar a transferência de carga entre as regiões do Brasil (Idem). Além disso, a ECT conta atualmente com cinco centros de logística integrada, estando localizados nos municípios do Rio de Janeiro, de Cajamar (SP), Brasília, Contagem (MG) e Curitiba (CORREIOS, 2020).

$\mathrm{O}$ aumento do e-commerce no Brasil e a real possibilidade de privatização da ECT vem tornando o país cada vez mais atrativo para os PSLs privados também ofertarem serviços de correios. Como é analisado por Cruz (2021), entre os anos de 2006 e 2016, o número de PSLs que ofertam atividades de correios passou de 204 para 410, um crescimento de 100,9\%.

A edição 242 da Revista Tecnologística (2016), especial sobre o comércio eletrônico, realizou uma entrevista com o operador logístico Sequioia, um dos pioneiros no Brasil no setor de e-commerce. A Sequioia foi 
fundada em 2010, surgiu no mercado logístico para atender o setor de moda e vestuário, no qual é líder no Brasil, principalmente em operações com encabidados, o que significa realizar toda a manipulação das mercadorias em cabides, incluindo o transporte. Armando Marchesan, diretor executivo da empresa, era um dos diretores na área de transporte fracionado da Submarino antes de fundar a Sequioia.

Inicialmente, a Sequioia buscou atender pequenos e-commerces, lojas e startups que necessitavam de serviços logísticos de distribuição e armazenagem. A empresa foi uma das pioneiras no Brasil na aplicação do conceito de condomínio de e-commerce, que consiste em ter os estoques de várias lojas dentro do mesmo centro de distribuição, no jargão logístico chamado de "e-condomínio". Com isso, a empresa consegue prestar vários serviços para diversas plataformas digitais menores ou startups, compartilhando não apenas a tecnologia interna dos galpões, mas também os sistemas de WMS

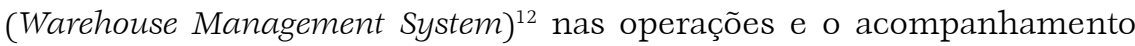
online em tempo real dos produtos de empresas que, individualmente, não poderiam arcar com os custos desse tipo de operação. Além do setor de moda, a empresa tem o setor de materiais escolares e a logística bancária (suprimentos bancários) como seus principais ramos de negócios. Atualmente, a empresa presta serviços para mais de 40 páginas digitais de clientes e-commerce, contando com armazéns nos estados de São Paulo, Minas Gerais, Rio de Janeiro e Santa Catarina.

Apesar de não ser oriunda do segmento de e-commerce, a Braspress, que é um dos maiores operadores logísticos do Brasil, também tem buscado parcerias com pequenos e médios clientes de e-commerce, contando com um leque variado de clientes na modalidade, de diversos portes (BRASPRESS, 2020).

Outro fator importante a ser analisado é a sazonalidade do comércio eletrônico, pois é comum que os operadores logísticos que atuam na área de e-commerce necessitem incrementar a mão de obra ou até mesmo a frota de veículos e armazéns para atender os pedidos de datas nas quais há maior demanda de produtos, como Black Friday e Natal. No Brasil há algumas datas que são consideradas sazonais (tabela 1). Analisando-se a tabela 1 , podemos estimar que durante $31,5 \%$ dos dias do ano as empresas estão se empenhando com estratégias específicas de marketing e vendas para as ditas 
datas sazonais. De acordo com os números do relatório do Webshoppers (2021), no dia dos namorados o faturamento do e-commerce cresceu $91 \%$, apresentando o maior crescimento entre as datas sazonais, enquanto o dia das mães é a data com maior entrada de novos consumidores.

\section{Tabela 1}

DIAS CONSIDERADOS DATAS SAZONAIS NO E-COMMERCE BRASILEIRO (RELATIVO À 2020)

\begin{tabular}{c|c|c}
\hline Data comemorativa & Período & Duração (dias) \\
\hline Sampa Week & 23/jan a 31/jan/2020 & 9 \\
Dia do Consumidor & 09/mar a 15/mar/2020 & 7 \\
Dia das Mães & 25/abr a 09/mai/2020 & 15 \\
Dia dos Namorados & 28/mai a 11/jun/2020 & 15 \\
Dia dos Pais & 25/jul a 08/ago/2020 & 15 \\
Dia das Crianças & 27/set a 11/out/2020 & 15 \\
Semana do Brasil & 04/set a 13/set/2020 & 10 \\
Single Day & 01/nov à 11/nov/2020 & 2 \\
Black Friday & 26/nov e 27/nov/2020 & 1 \\
Cyber Monday & 30/nov/20 & 15 \\
Natal & 10/dez a 24/dez/2020 & \\
\hline Total de dias & $\mathbf{1 1 5}$ & \\
\hline
\end{tabular}

Elaboração: Elaborado pelo autor com base em Webshoppers (2021).

Essas datas, seja por razões culturais ou por estratégias de giro de estoques, são amplamente exploradas pelo marketing empresarial e costumam demandar flexibilidade para os PSLs. No entanto, cada vez mais os operadores logísticos estão mais adaptados às flutuações do mercado, contando com estruturas flexíveis que normalmente atuam com determinada capacidade ociosa.

A rede logística (SAVY, 1993), na qual se assenta uma das bases do e-commerce, está associada intimamente com o espaço geográfico. O número e a localização de depósitos e centros de distribuição, por exemplo, podem ser problemas ou soluções para PSLs conseguirem atrair novos clientes. O fator espacial é fundamental na solução desse tipo de problema, pois a localização e o tipo dos galpões - somados ao maquinário e à tecnologia operacional - podem resultar em serviços diferenciados, além de encarecer ou baratear os custos logísticos. A Netshoes, por exemplo, 
tem um centro de distribuição em Barueri (SP), que atende à RMSP, e um centro de distribuição na pequena cidade de Extrema (MG), que tem acesso estratégico entre a RMSP e Campinas (SP), bem como facilidade para acessar a rodovia Presidente Dutra, principal eixo de ligação entre os estados de São Paulo e Rio de Janeiro.

\section{Imagem 2}

CENTRO DE DISTRIBUIÇÃO DA NETSHOES NO MUNICÍPIO DE EXTREMA (MG), 2019

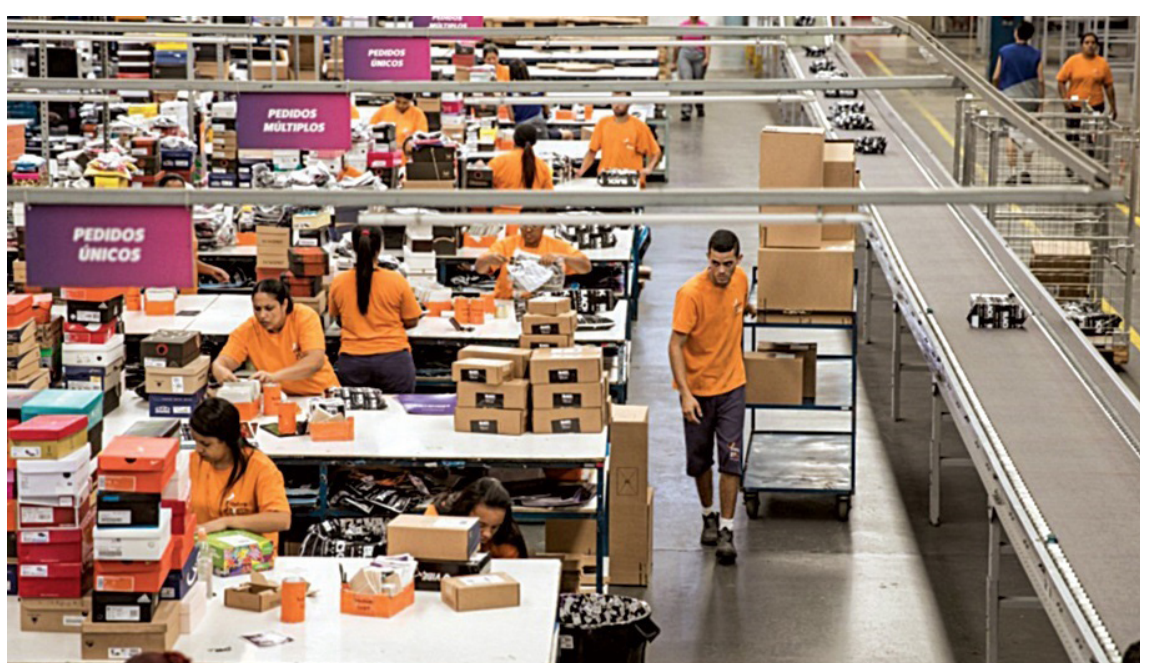

Fonte: Terra Economia, 2019.

Empresas como o Magazine Luiza, a Netshoes, a Centauro, o Mercado Livre, as Americanas e outras grandes do e-commerce nacional costumam ter vários PSLs e operadores logísticos como parceiros, escolhendo-os de acordo com uma série de fatores como preços, capacidade e experiência no manuseio de cargas específicas, disponibilidade, localização da entrega, tempo de entrega, tempo de parceria etc.

Apesar de o Brasil ser atualmente o maior mercado de e-commerce da América Latina e o $10^{\circ}$ maior do mundo em faturamento, as transações ainda são bastante inferiores (tanto em número de encomendas como em faturamento) aos números de China, Estados Unidos e Reino Unido, respectivamente os maiores mercados do comércio digital no mundo (BAGATINI; LAIMER, 2019). Para se ter ideia, só em 2018, 50 bilhões de pacotes foram despachados na China via e-commerce (EL PAÍS, 2019). 
O jornal El País realizou uma matéria analisando o dinamismo do mercado de e-commerce chinês, no ano de 2019. De acordo com a reportagem, o mercado chinês é o mais competitivo e trabalha com a menores tarifas, apostando nas vendas em escala. A competitividade do mercado chinês é tão agressiva que "afugentou grandes multinacionais, como a Amazon, incapazes de abrirem caminho no campo minado que é o mercado chinês" (Idem). De acordo com a mesma reportagem, houve um crescimento sem precedentes na demanda por armazéns na segunda década do século XXI: no ano de 2018 ocuparam mais de 50 milhões de metros quadrados; por outro lado, houve uma corrida tecnológica para automatizá-los e obter assim uma maior eficiência das operações. Há espaço para a melhora, porque o custo da logística na China é de $14,6 \%$ do PIB, quase o dobro dos 7,7\% nos Estados Unidos (EL PAÍs, 2019).

A Suning Commerce Grup é um dos maiores grupos varejistas da China no modelo de e-commerce B2C, com sede em Nanjing, província de Jiangsu. A Suning possui mais de 1.600 lojas, cobrindo mais de 300 cidades da China (China continental e Hong Kong), além do Japão (SUNING, 2020). Em entrevista ao Jornal El Pais (2019), Xue Fanhai (subdiretor de instalações da Suning) afirmou que os custos operacionais na China, do imobiliário à mão de obra, aumentaram grandemente na segunda década do século XXI. Sendo assim, para se manterem competitivas, as empresas chinesas vêm incrementando elementos para otimizar a eficiência e a rentabilidade na mesma medida. Neste aspecto, de acordo com o mesmo entrevistado, a "tecnologia é chave", pois o processo de automação das atividades logísticas só tende a crescer, atenuando os impactos da elevação dos custos nas empresas. De acordo com a Revista Tecnologística (2016), algumas tendências para entregas de e-commerce é o uso de drones e veículos driveless (sem motorista), já em experimento pela Amazon, pelo DHL e pelo Google nos Estados Unidos.

Com a pandemia da Covid-19, os serviços de e-commerce ganharam mais protagonismo no comércio brasileiro e mundial, uma vez que muitas pessoas passaram a evitar as aglomerações humanas oferecidas pelos grandes centros comerciais, atacadistas e varejistas tradicionais, optando cada vez mais por receber suas compras em suas residências, como bem analisou o geógrafo espanhol Ricardo Méndez ${ }^{13}$ : 
Por um lado, a demanda por terrenos e galpões logísticos aumenta após o crescimento das compras online durante o confinamento e das boas perspectivas para o comércio eletrônico, gerando uma demanda crescente pela instalação de centros de distribuição locais complementares (city hubs), que facilitem a distribuição interna em áreas mais próximas aos centros das cidades do que as atuais plataformas suburbanas ou periurbanas (MÉNDEZ, 2020, p. 101) ${ }^{14}$.

A Associação Brasileira de Operadores Logísticos (ABOL) promoveu uma entrevista com gestores de alguns dos principais operadores que atuam no Brasil, como DHL, FedEx, Penske, FM Logistics, Braspress, Multilog, Ativa Logística e JSL, destacando as alterações operacionais provocadas pela pandemia da Covid-19 em 2020:

a) Enquanto algumas empresas sofreram muito durante o início da crise, como as do setor automotivo, de autopeças, linha branca e eletroeletrônicos, as vendas do e-commerce, no primeiro semestre, por exemplo, chegaram a registrar um crescimento de $145 \%$;

b) A pandemia mudou o perfil de distribuição na cadeia de suprimentos. As vendas de alguns mercados, como moda e automóveis, por exemplo, caíram, por falta de compradores. Por outro lado, itens básicos e de saúde tiveram picos de demanda. Até mesmo no transporte terrestre cresceram as oportunidades, uma vez que a malha aérea para passageiros diminuiu fortemente, afetando também o transporte aéreo de cargas;

c) O e-commerce mudou um pouco de espectro. A predominância deixou de ser do business to business (compras entre empresas, $\mathrm{B} 2 \mathrm{~B}$ ), e passou a ser para as pessoas físicas (business-to-consumer, B2C) (ABOL, 2020).

No Brasil, alguns operadores logísticos e transportadoras enfrentaram o aumento abrupto dos pedidos de entregas urbanas. De acordo com a reportagem publicada pela Folha de São Paulo em outubro de 2020 (FOLHA, 2020), os mesmos estão passando por dificuldades para conseguir aumentar suas frotas de veículos, isto porque o prazo de entrega de novos caminhões nas concessionárias cresceu devido às filas de pedidos e às restrições de operação por conta das exigências sanitárias para evitar a propagação do vírus. 


\section{Considerações Finais}

O e-commerce deixou de ser uma tendência e se tornou uma realidade na sociedade brasileira, bem internalizada, tornando-se gradualmente habitual para grande parcela da população na segunda metade da década de 2010. Podemos identificar três eventos que foram fundamentais para a solidificação e a expansão do e-commerce no país: a popularização do uso da internet, a difusão do uso de smartphones e a pandemia da Covid-19.

Apesar de o e-commerce ter crescido bastante no Brasil, se analisarmos economias mais maduras, podemos inferir que ainda há muita capacidade de expansão para o comércio digital no país. Embora ainda haja uma significativa parcela da população com níveis de renda próximos à subsistência, elevadas taxas de desemprego, residências sem acesso à internet etc., se resolvidos esses problemas, há grande possibilidade de expansão do mercado de e-commerce brasileiro.

Outro problema que gradualmente está sendo resolvido é a questão da extensão territorial do Brasil, pois, a rigor, é um fator que dificulta o comércio digital porque, dependendo da localização do comprador e do vendedor, há complicações logísticas para entregar o produto e custos elevados com transporte. No entanto, como podemos ver em Cruz (2021), com a expansão do número de PSLs para áreas mais interioranas e sua incorporação às redes de operadores logísticos, a questão da extensão territorial vem sendo superada.

\section{Notas}

1 Professor Titular de Transportes e Logística na Escola Politécnica da USP, em São Paulo, e na Universidade Federal de Santa Catarina, em Florianópolis. Atualmente é professor e pesquisador na área de Transporte e Logística, no Programa de Pós-Graduação em Engenharia da Produção, da Universidade Federal de Santa Catarina, em Florianópolis. Novaes orientou diversos dos pesquisadores que atualmente trabalham com temáticas como planejamento das infraestruturas de transportes e gerenciamento da cadeia de suprimentos e armazenagem. Autor de diversos livros e artigos sobre a temática, Novaes é, atualmente, uma das principais referências nos estudos sobre transportes e logística no Brasil.

2 Ricardo Castillo (UNICAMP) desenvolve e orienta alguns importantes estudos para o entendimento da logística do agronegócio brasileiro, sobretudo sobre a Região Centro-Oeste.

3 Márcio Rogério Silveira (UFSC) é líder do Grupo de Estudos em Desenvolvimento Regional e Infraestruturas (GEDRI), orientando vários pesquisadores em estudos sobre transportes de cargas e passageiros em todos os modais de transporte. 
4 Roberto França Silva Júnior (UNILA) realiza pesquisas sobre áreas de fronteiras e recintos alfandegados, bem como já produziu textos teóricos sobre transporte rodoviário e o papel da Empresa Brasileira de Correios e Telégrafos (ECT) para a logística nacional.

5 Nelson Fernandes Felipe Júnior (UNILA) tem como ênfase estudos sobre a logística marítimo-portuária, também orientando alunos na mesma temática.

6 Igor Venceslau desenvolve a Tese de doutorado em Geografia pela USP intitulada "O comércio eletrônico na difusão do meio técnico-científico-informacional no Brasil: usos do território e estratégias logísticas".

7 Realizado pela Ebit desde 2001, o Webshoppers é o relatório de maior credibilidade sobre o comércio eletrônico brasileiro e considerado a principal referência para os profissionais do segmento.

8 Ato de folhear aleatoriamente as páginas e as linhas de um texto na tela.

9 Novaes (2007, p. 75-6) destaca que "um site de comércio eletrônico na Internet permite que se levantem informações sobre os usuários, à medida que navegam pelo site. Uma forma de se fazer isso é a implantação de cookies, que são pequenos arquivos colocados pelo servidor nos computadores dos clientes potenciais e que permitem a recuperação de valiosas informações sobre eles. Utilizando técnicas estatísticas sofisticadas, os analistas descobrem pistas de grande valor para as vendas e para o marketing, envolvendo perfil do consumidor, preferências, hábitos de compra (horários mais utilizados, dias do mês, volume de compras etc.). Mesmo não fazendo uso dos cookies, os provedores podem colher informações importantes sobre seus clientes a partir de seus hábitos e frequência de compras, faixa etária, sexo etc.".

10 De acordo com a Associação Brasileira de Operadores Logísticos (ABOL). Operador Logístico (OL) é "a pessoa jurídica capacitada a prestar, através de um ou mais contratos, por meios próprios e/ou por intermédio de terceiros, os serviços de transporte (em qualquer modal), armazenagem (em qualquer condição física ou regime fiscal) e gestão de estoque (utilizando sistemas e tecnologia adequada)" (ABOL, 2019).

11 Informações obtidas no levantamento da Revista Tecnologística (2016).

12 É um aplicativo que apoia as atividades operacionais no processo de armazenagem. Inclui as atividades de recebimento, inspeção, endereçamento, armazenagem, separação, embalagem. carregamento, expedição, emissão de documentos e controle do estoque.

13 Ricardo Méndez publicou recentemente um livro chamado "Sitiados por la pandemia” (2020), no qual retrata as mudanças ocorridas na economia espanhola e europeia - também fazendo comparativos com países de todos os continentes -, bem como mudanças e tendências comportamentais dos fluxos de pessoas e mercadorias durante e após o período de pandemia.

14 Tradução nossa do original: "Por un lado, el suelo y las naves logísticas aumentan su demanda tras el incremento de las compras online durante el confinamiento y las buenas perspectivas para el comercio electrónico, planteándose una creciente demanda para instalar centros de distribución complementarios de proximidad (city hubs), que faciliten el reparto interno, en áreas más próximas al centro de las ciudades que las actuales plataformas suburbanas 0 periurbanas" (MÉNDEZ, 2020, p. 101). 


\section{Referências}

ABOL. 0 e-commerce sustenta o transporte de cargas. 2020. Disponível em: < https://abolbrasil.org.br/posts/e-commerce-sustenta-transporte-de-cargas/ > . Acesso em 28 de abril de 2021.

Definição de Operador Logístico. Disponível em: < http:// abolbrasil.org.br/conteudo/20 > . Acesso em 23 de junho de 2019.

BAGATINI, F. Z; LAIMER, C. G. O Contexto do e-commerce no Brasil: Análise do Desempenho do Varejo Online no Período de 2003 a 2018. In: CONGRESSO LATINO-AMERICANO DE VAREJO E CONSUMO:"BUILDING PURPOSE THROUGH STAKEHOLDERS IN RETAILING", 13., São Paulo, 2019. Proceedings... São Paulo: FGV, 2019. p. 1-15.

BRASPRESS. Página inicial (Home). Disponível em: < https://www.braspress. com/ > . Acesso em 27 de dezembro de 2020.

CAMARGOS, A. P. Desafios da difusão da Internet nos países em desenvolvimento: estudo de caso do Brasil. Comunicação e Sociedade, v. 28, p. 127-141, 1997. CORREIOS. Relatório de administração de 2018. Disponível em: <https:// www.correios.com.br/acesso-a-informacao/institucional/publicacoes/relatorios/ relatorios-de-administracao/pdf/RelatoriodeAdministraoExercicio2018.pdf >. Acesso em 23 de março de 2020.

CRUZ, W. L. M. A expansão dos Prestadores de Serviços Logísticos (PSLs) no Brasil nas duas primeiras décadas do século XXI: agentes, processos e tendências. 2021. 319 f. Tese (Doutorado em Geografia) - Centro de Filosofia e Ciências Huamnas, Universidade Federal de Santa Catarina, Florianópolis, 2021.

EL PAÍS. A revolução logística chinesa que deixa a Amazon no chinelo. 2019. Disponível em: <https://brasil.elpais.com/brasil/2019/07/05/ economia/1562362005_685829.html?fbclid=IwAR2arGyJAtjiW6Pm0jMxiAz yKiHuCAKk1Z17IR7Vf-vY3OK_GHEoSro8Ifc>. Acesso em 28 de abril de 2020.

FOLHA DE SÃO PAULO. Transportadoras têm dificuldades em obter novos caminhões. 2020. Disponível em:< https://www1.folha.uol.com.br/ mercado/2020/10/transportadoras-ainda-nao-conseguem-caminhoes-novos. shtml >. Acesso em 17 de novembro de 2020.

GV EXECUTIVO. Um novo momento para o e-commerce, v. 15, n. 1, jan./ jun. 2016.

INTERNATIONAL TELECOMMUNICATION UNION (ITU). Series ICT data for world, by geographic regions and by level development, for the following 
indicators. Disponível em: < https://www.itu.int/en/ITU-D/Statistics/Pages/stat/ default.aspx > . Acesso em 30 de abril de 2020.

MÉNDEZ, R. Sitiados por la pandemia. Del colapso a la reconstrucción: apuntes geográficos. Madrid: Ed. Revives, 2020.

NOVAES, A. G. Logística e gerenciamento da cadeia de distribuição. Rio de Janeiro: Elsevier, 2007.

REVISTA TECNOLOGÍSTICA. Especial: e-commerce. 2016. Disponível em: < https://www.tecnologistica.com.br/portal/revista/edicao-anterior/242/ > . Acesso em 28 de abril de 2021.

SANTOS, A. S.; MIRANDA, G. J. E-commerce no Brasil: se o segmento é promissor, por que empresas atuantes estão no vermelho? Revista Evidenciação Contábil \& Finanças, João Pessoa, v. 3, n. 1, p. 54-68, jan. /abr. 2015.

SANTOS, D. R. et al. Vendas no varejo eletrônico (via internet) no Brasil antes e depois da popularização dos smartphones. Brazilian Applied Science Review, Curitiba, v. 2, n. 5, p. 1566-1578, out./dez. 2018.

SAVY, M. Logistique et territoire (article). Espace géographique, tome 22, n. 3 , p. 210-218, 1993.

SILVA JÚNIOR, R. F; OLEGÁRIO, P. T. Da lenta circulação postal no "Arquipélago Brasil" à integração logística do território: o papel estratégico dos Correios na geopolítica e na integração do território. Boletim Campineiro de Geografia, v. 6, n. 1, p. 45-66, 2016.

SUNING. Home page. 2020. Disponível em: < https://www.suning.com/ > . Acesso em 03 de maio de 2020.

TERRA ECONOMIA. Magazine Luiza vai lucrar com a Netshoes? 2019. Disponível em: < https://www.istoedinheiro.com.br/o-magazine-luiza-vai-lucrarcom-a-netshoes/>. Acesso em 28 de abril de 2021.

WEBSHOPPERS. Relatório sobre e-commerce 2018. 2020. Disponível em: $<$ https://www.ebit.com.br/webshoppers/webshoppersfree >. Acesso em 27 de abril de 2020.

Relatório sobre e-commerce 2020 (n 43). 2021. Disponível em: < https://company.ebit.com.br/webshoppers/webshoppersfree >. Acesso em 30 de abril de 2021.

Recebido em: 05/05/2021

Aceito em: 11/05/2021 